\title{
Novel drug-regulated transcriptional networks in brain reveal pharmacological properties of psychotropic drugs
}

Michal Korostynski*, Marcin Piechota, Jaroslaw Dzbek, Wiktor Mlynarski, Klaudia Szklarczyk, Barbara Ziolkowska and Ryszard Przewlocki

\begin{abstract}
Background: Despite their widespread use, the biological mechanisms underlying the efficacy of psychotropic drugs are still incompletely known; improved understanding of these is essential for development of novel more effective drugs and rational design of therapy. Given the large number of psychotropic drugs available and their differential pharmacological effects, it would be important to establish specific predictors of response to various classes of drugs.

Results: To identify the molecular mechanisms that may initiate therapeutic effects, whole-genome expression profiling (using 324 Illumina Mouse WG-6 microarrays) of drug-induced alterations in the mouse brain was undertaken, with a focus on the time-course $(1,2,4$ and $8 \mathrm{~h}$ ) of gene expression changes produced by eighteen major psychotropic drugs: antidepressants, antipsychotics, anxiolytics, psychostimulants and opioids. The resulting database is freely accessible at www.genes 2 mind.org. Bioinformatics approaches led to the identification of three main drug-responsive genomic networks and indicated neurobiological pathways that mediate the alterations in transcription. Each tested psychotropic drug was characterized by a unique gene network expression profile related to its neuropharmacological properties. Functional links that connect expression of the networks to the development of neuronal adaptations (MAPK signaling pathway), control of brain metabolism (adipocytokine pathway), and organization of cell projections (mTOR pathway) were found.

Conclusions: The comparison of gene expression alterations between various drugs opened a new means to classify the different psychoactive compounds and to predict their cellular targets; this is well exemplified in the case of tianeptine, an antidepressant with unknown mechanisms of action. This work represents the first proof-ofconcept study of a molecular classification of psychoactive drugs.
\end{abstract}

Keywords: Gene expression patterns, Psychotropic drugs, Striatum, Molecular classification

\section{Background}

The complex etiology and heterogeneity of mental disorders is associated with moderate effectiveness of psychoactive drugs, frequent recurrence of symptoms and high cost of therapy [1]. Psychotropic drugs have diverse therapeutic profiles (Table 1), and even a single class drugs can show high diversity of effectiveness and effects may be limited to particular sub-types of a given disorder, exemplified by the various subclasses of antidepressants [2]. On

\footnotetext{
* Correspondence: michkor@if-pan.krakow; nfprzewl@cyf-kr.edu.pl Department of Molecular Neuropharmacology, Institute of Pharmacology Polish Academy of Sciences, Smętna 12, PL 31-343, Kraków, Poland
}

the other hand, drugs belonging to different therapeutic classes may have effects that are either beneficial or adverse in a particular disease. Therefore, the identification of common and specific neurobiological actions of psychoactive compounds is critical to understanding therapeutic mechanisms. Furthermore, comparison of drug-induced molecular profiles may provide objective criteria for a more rational classification of psychotropic drugs.

The development of maladaptive neuroplastic changes is suggested to underlie the progression of neuropsychiatric disorders [3]. The pattern of structural alterations in the brain is determined by the process of synaptic plasticity and

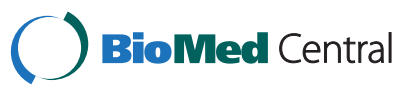


Table $1 \mathrm{~A}$ list of psychotropic drugs selected for the comparison

\begin{tabular}{|c|c|c|c|c|}
\hline & Drug & Dose [mg/kg, i.p.] (control) ${ }^{1}$ & Pharmacological targets & Clinical group $^{7}$ \\
\hline 1 & Mianserin $(\mathrm{MIA})^{3}$ & $20($ sal) & HRH1 / HTR2C, 2A, 3A / ADRA2C, 2A, 1A / NET / CHRM & Antidepressant (NaSSa) \\
\hline 2 & Imipramine $(\mathrm{IMI})^{3}$ & 10 (sal) & SERT / HRH1 / NET / ADRA1A / HTR2C / CHRM & Antidepressant (TCA) \\
\hline 3 & Fluoxetine $(F L U)^{3}$ & 20 (sal) & SERT / NET / HTR2C & Antidepressant (SSRI) \\
\hline 4 & Bupropion $(B \cup P)^{3}$ & 20 (sal) & DAT & Antidepressant (DRI) \\
\hline 5 & Tianeptine $(T \mid A)^{2}$ & 20 (sal) & Unknown targets & Antidepressant (SSRE) \\
\hline 6 & Tranylcypromine $(\text { TRA })^{2}$ & 20 (sal) & MAO & Antidepressant (MAOI) \\
\hline 7 & Methamphetamine $(\mathrm{MET})^{2}$ & 2 (sal) & NET / DAT & Psychostimulant \\
\hline 8 & Cocaine $(\mathrm{COC})^{2}$ & 25 (sal) & DAT / NET / SERT & Psychostimulant \\
\hline 9 & Nicotine $(\mathrm{NIC})^{2}$ & 1 (sal) & $\mathrm{n}-\mathrm{AChR}$ & Psychostimulant \\
\hline 10 & Heroin $(\mathrm{HER})^{6}$ & 10 (sal) & OPRM1, OPRK1, OPRD1 & Analgesic \\
\hline 11 & Morphine $(\mathrm{MOR})^{4}$ & 20 (sal) & OPRM1, OPRK1, OPRD1 & Analgesic \\
\hline 12 & Ethanol $(E T O)^{2}$ & 2000 (sal) & GABAA & Anxiolytic/Analgesic \\
\hline 13 & Diazepam $(\mathrm{D} \mid \mathrm{A})^{2}$ & 5 (twe) & GABAA & Anxiolytic \\
\hline 14 & Buspirone (BUS) ${ }^{3}$ & 10 (sal) & $5 \mathrm{HT} 1 \mathrm{~A}$ & Anxiolytic \\
\hline 15 & Hydroxizine $(H Y D)^{2}$ & 10 (sal) & $\mathrm{HRH}$ & Anxiolytic \\
\hline 16 & Clozapine $(\mathrm{CLO})^{3}$ & 3 (twe) & DRD4, 2 / HRH1 / HTR2A, 2C / DRD1 / CHRM / ADRA1A & Antipsychotic \\
\hline 17 & Risperidone $(\mathrm{RIS})^{3}$ & 0.5 (twe) & HTR2A, 2C / DRD1 / DRD2, 3, 4 / ADRA1A, 2C / HRH1 & Antipsychotic \\
\hline 18 & Haloperidol $(\mathrm{HAL})^{3}$ & 1 (twe) & $\mathrm{DRD} 2,3,4$ / 5HT2 & Antipsychotic \\
\hline 19 & Tween $80^{2}$ & vol. 10 ml/kg (naïve) & No targets & Vehicle \\
\hline 20 & Saline $(S A L)^{5}$ & vol. 10 ml/kg (naïve) & No targets & Vehicle \\
\hline
\end{tabular}

${ }^{1}$ the effective drug doses were based on the literature; the drugs were purchased from ${ }^{2}$ Sigma-Aldrich, ${ }^{3}$ Biotrend, ${ }^{4}$ Teva, ${ }^{5} \mathrm{Polpharma}$ or ${ }^{6}$ synthesized from morphine, ${ }^{7}$ class of antidepressant (NaSSa, noradrenergic and specific serotonergic antidepressant, TCA tricyclic antidepressant, SSRI selective serotonin reuptake inhibitor, DRI dopamine reuptake inhibitor, SSRE selective serotonin reuptake enhancer, MAOI monoamine oxidase inhibitor).

is influenced by genetic, neurodevelopmental and environmental factors [4]. It is thought that therapeutic agents reverse disease-related alterations by reconstruction and normalization of neuronal connections in targeted brain areas [5,6]. This view is supported by the fact that the therapeutic effects of psychotropic drugs usually have delayed onset and gradually increase with time. Establishment of these long-lasting changes requires gene expression and synthesis of new proteins [7-9] in a time-dependent and region-specific manner; such changes may serve as early markers of drug-activated biological processes.

Impaired control over drive and motivation is a frequent symptom in psychiatric disorders, including depression, mania and addiction $[10,11]$. Since these conditions are characterized by disturbed monoaminergic function, most current pharmacotherapies target receptors and transporters for dopamine, serotonin and noradrenaline as well as other transmitters such as GABA and acetylcholine [12,13]. All of these transmitter systems are represented in the striatum, a brain region responsible for control of motivation, reward-based learning and decision-making [14,15]. The striatum as an evolutionarily ancient brain region reveals comparable functions and gene expression profiles between rodents and humans [16]. Thus, despite the limitations of an animal model [17], the comparison of drug-induced dynamic alterations in the rodent striatal gene expression profile provides insights into molecular mechanisms of psychotropic drug actions.

In this study, using whole-genome gene expression microarrays we identified main drug-responsive genomic networks that are regulated by 18 individual psychoactive drugs known to impact on one or more pharmacological targets within the striatum. This work introduces a novel approach for the classification of psychotropic drugs on the basis of gene expression profiling. To encourage further discoveries along these lines, we made freely available the entire interactive database which contains the results of the present study (www.genes2mind.org).

\section{Results}

Drug-induced transcriptional alterations in the striatum Using whole-genome microarrays (Illumina MouseWG-6), we compared striatal gene expression profiles (magnitude and dynamics of $\sim 30,000$ genes) produced by 18 major psychoactive drugs at 1, 2, 4 and 8 hours after acute administration (Table 1). Obtained data were subjected to two-way analysis of variance (ANOVA) with drug and time as factors (Additional file 1). We found 317 drug-responsive transcripts in the striatum at the most conservative statistical 
threshold $(\mathrm{P}<0.05$ after Bonferroni correction, nominal $\left.\mathrm{P}=1.36 \times 10^{-06}\right)$. After removal of genes represented more than once on the microarrays, this list contains 278 unique genes. For down-stream analyses we selected top 300 transcripts ordered by genes 2 mind score, which takes into account fold of change and direction of drug-induce gene expression alterations (please see Methods for details). This method was implemented in the genes2mind selection module (www.genes2mind.org). Furthermore, we estimated total number of genes regulated by psychotropic drugs by calculation of true positives over a wide range of false discovery rates (FDR). This estimation indicated that the total number of regulated transcripts slightly exceeds one thousand (Additional file 2). Therefore, with the restrictive statistical approach we identified about $30 \%$ of drug-responsive genes in the striatum. For canonical pathway analysis we used 5\% FDR threshold at which we identified most of drug-regulated transcripts (872 microarray probes). The number of genes regulated by each drugs in the timecourse (genes2mind score $>10$ ) is presented in Additional file 3. All the additional analyses and comparisons (including selection of drugs, genes and time-points) are available at the genes $2 \mathrm{mind}$ resource.

\section{Molecular classification of psychotropic drugs}

We used hierarchical clustering and principal component analysis (PCA) of the 300 drug-responsive transcripts (defined by genes 2 mind score using all the time-points) to classify psychotropic drugs. Druginduced transcriptional signatures were distinguished between the various therapeutic groups: anxiolytics (buspirone, diazepam and hydroxyzine), atypical antipsychotics (clozapine and risperidone), opioids (morphine and heroin) and psychostimulants (methamphetamine and cocaine) (Figure 1A). However, the expression profile of the antipsychotic drug - haloperidol was similar to that of psychostimulants and tranylcypromine. Also, the effects of nicotine resembled those of addictive drugs, ethanol and opioids, more closely than other psychostimulants. Antidepressants proved to be the most heterogeneous group of drugs in terms of their impact on gene expression, with mianserin, imipramine, tranylcypromine and fluoxetine displaying very diverse profiles. The gene expression profile of mianserin was most similar to those elicited by atypical neuroleptics; the profiles obtained in response to imipramine were similar to those produced by anxiolytics; and tranylcypromine generated a profile that resembled that obtained with psychostimulants. Nevertheless, antidepressants that target monoamine transporters (fluoxetine and bupropion) fell into one cluster.

Three main PCA components explained 56\% of the variance in gene expression and mapped the test drugs in three-dimensional space according to their molecular profiles (Figure 1B). The first PCA component represented the strong effects of opioids, ethanol and tranylcypromine; there were no detectable effects of diazepam and hydroxyzine. The second principal component included the full spectrum of drug-induced effects in the striatum - from substantial inhibition of gene
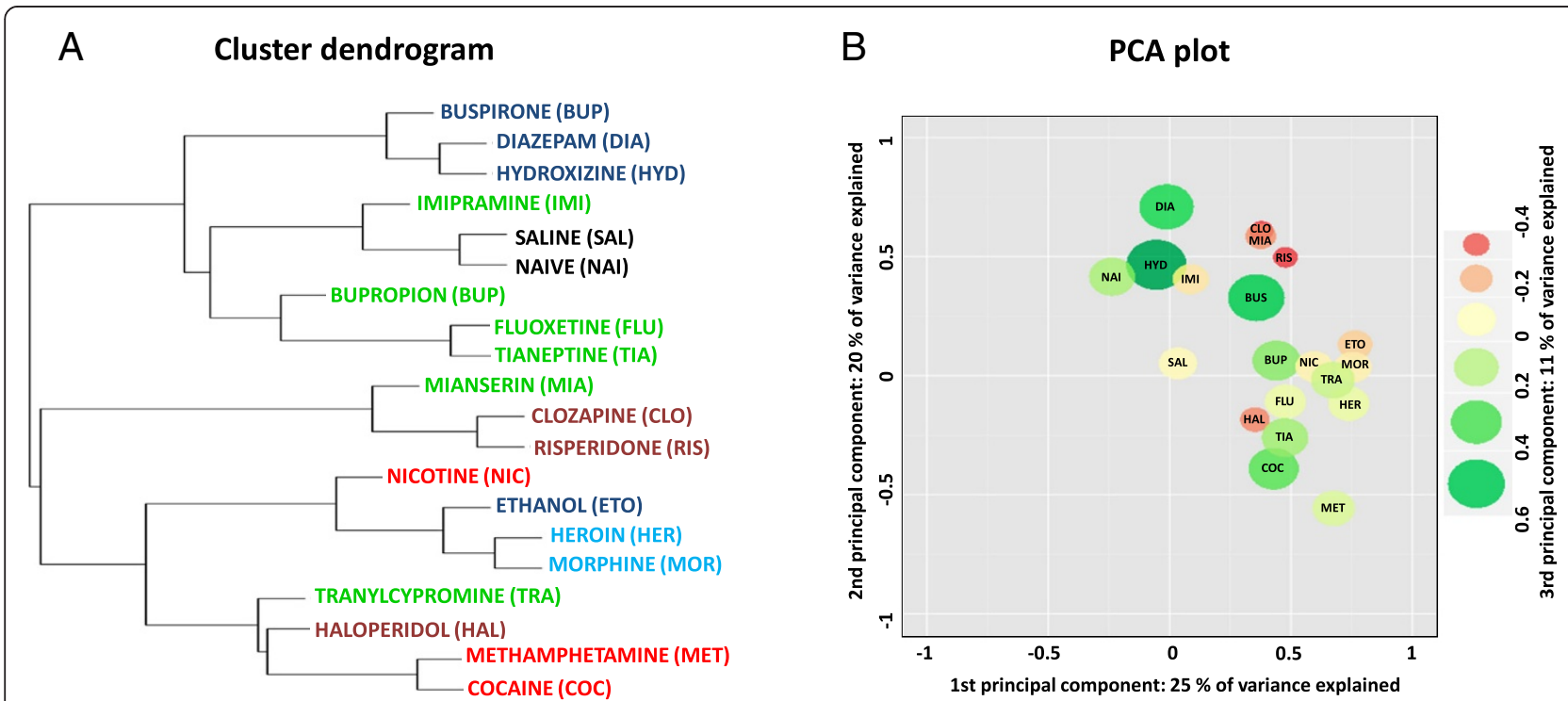

Figure 1 A comparison of psychotropic drugs based on pattern of gene expression alterations in the striatum. Cluster dendrogram (A) and PCA plot (B) were generated based on expression profile of top 300 drug-responsive genes. Distance between drugs corresponds to a divergence in the profile of drug-induced transcriptional alterations. Therapeutic classes of drugs are coded by colors presented on the clustering (green for antidepressants, red for psychostimulants, blue for anxiolytics, brown for antipsychotics and light blue for opioids). First and second components of PCA are shown on $\mathrm{x}$ and $\mathrm{y}$ axis, while third component is coded by color and size of the circles as presented on the right. 
expression by diazepam or clozapine to strong activation by cocaine and methamphetamine. The third PCA component showed, on one hand, a common effect of antipsychotic drugs and mianserin, and on the other, a common effect of all three anxiolytics.

\section{Drug-induced gene expression networks}

To connect effects of psychotropic drugs to inducible gene expression patterns in the striatum, we determined the correlation between loadings of the first three PCA components and the level of transcriptional alterations. Hierarchical clustering was used to search for druginducible groups of co-expressed genes (Figure 2A). Three main drug-responsive gene clusters, representing network $\alpha$ (containing 105 transcripts), $\beta$ (43 transcripts) and $\gamma$ (27 transcripts) became evident. The clusters revealed diverse drug- and time-dependent patterns of up- and down-regulation of gene expression (see Figure 3 for examples of typical genes). Next, a map of the complete striatal transcriptome, based on the level of correlation between profiles of all transcripts measured using microarrays, was developed in order to depict drug-induced alterations in expression. All three drugresponsive gene clusters are located on the same branch of a tree (Additional file 4). The clusters were clearly separated and organized in drug-regulated genomic networks (Figure 2B). We found no other networks with distinct gene expression patterns. However, it is possible to identify subclusters of genes with moderately different profiles of expression within the three main networks (Additional file 5).

Expression of gene network $\alpha$ correlated with the second PCA component. Drug-induced changes in network $\alpha$ genes were bidirectional, e.g. methamphetamine

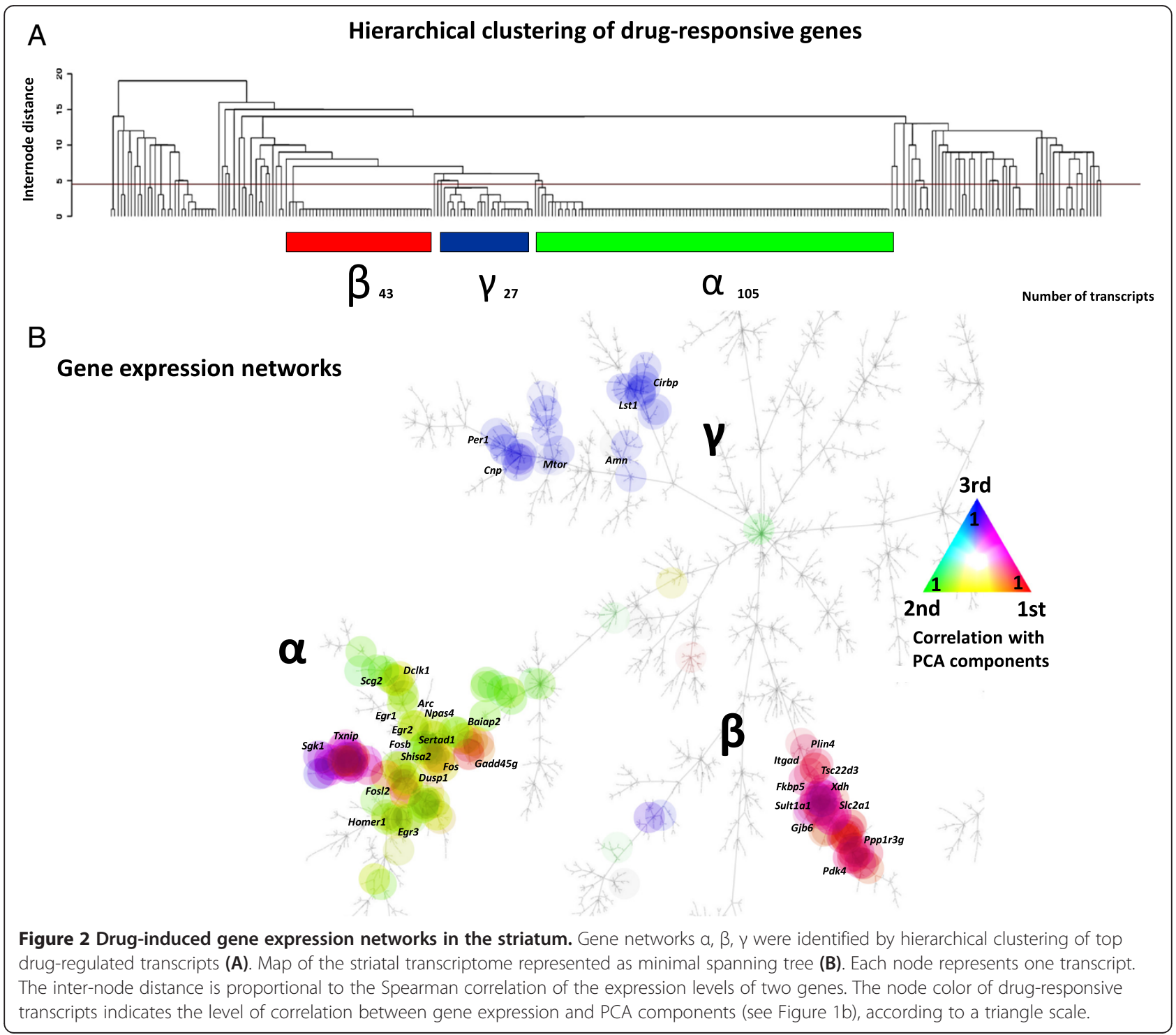




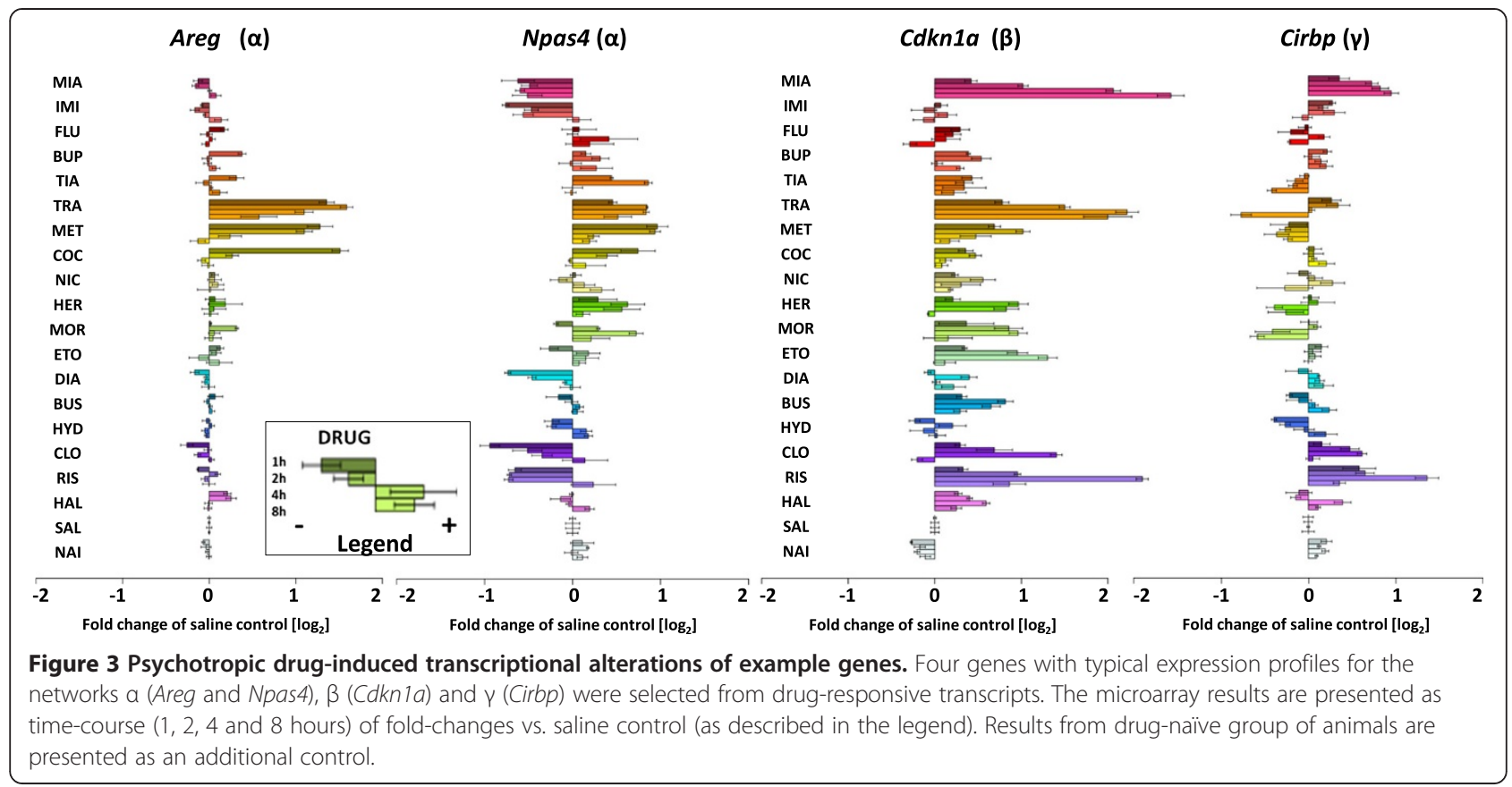

induced expression of Npas4 and Egr1, while diazepam inhibited it. Buspirone, mianserin and risperidone induced some activity-dependent genes but downregulated others, e.g. mianserin inhibited expression of Homer 1 by 0.6 -fold and induced Fos by 2.3 -fold. The gene expression network $\beta$ correlated with the first PCA factor. The expression of this network was regulated to a different degree by drugs from various pharmacological groups, e.g. Cdkn1a or Fkbp5 after opioids and tranylcypromine, except that diazepam, hydroxyzine and imipramine had no effects. The expression of gene network $\gamma$ correlated with the third PCA component. All network $\gamma$ genes were regulated by risperidone, mianserin and clozapine, in a bidirectional manner, e.g. Cirbp and Mtor were strongly up-regulated by atypical neuroleptics and mianserin, but down-regulated by tranylcypromine or methamphetamine.

\section{Functional description of drug-regulated gene networks Cell-type enrichment of drug-responsive genes}

Identification of the types of neural cells expressing genes from the $\alpha, \beta$ and $\gamma$ networks was carried out by reference to publicly available data that represents cellular enrichment of individual transcripts in neurons, astrocytes or oligodendrocytes (Figure 4) [18]. Significant enrichment of transcripts from the expression network $\alpha$

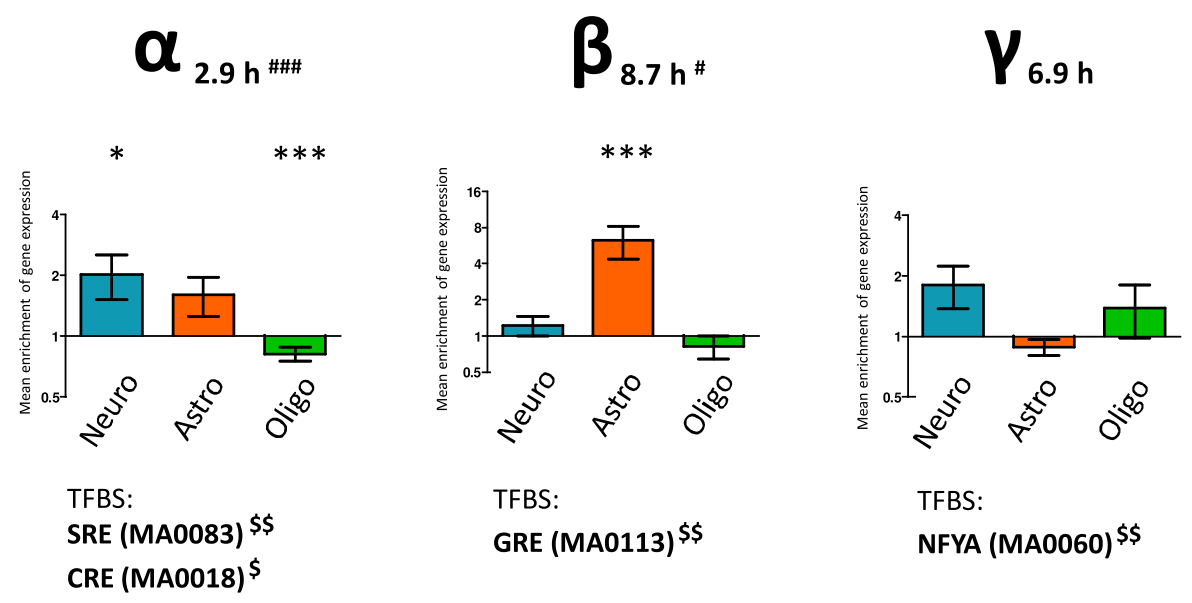

Figure 4 Functional analysis of drug-induced gene networks $\boldsymbol{\alpha}, \boldsymbol{\beta}$ and $\boldsymbol{\gamma}$. The networks were described by gene enrichment in neurons, astrocytes and oligodendrocytes, overrepresentation of transcription factor binding sites (TFBS) and median mRNA half-life (median for wholetranscriptome $=5.6 \mathrm{~h}$ ); significance of enrichment: ${ }^{*} \mathrm{P}<0.05$, ${ }^{* *} \mathrm{P}<0.01,{ }^{* * *} \mathrm{P}<0.001$. 
was found in neurons (e.g. neuron-specific Npas4, Scg2 or Baiap2) and under-representation in oligodendrocytes. Gene network $\beta$ was characterized by very strong over-representation of genes expressed in astrocytes, including the cell-type specific markers Gjb6 and Ppp1r3g. Network $\gamma$ genes did not show enrichment in any particular cell type although individual genes that were highly expressed in either neurons (Amn and Lst1) or oligodendrocytes $(\mathrm{Cnp})$ were identified.

\section{Over-representation of transcription factor binding sites}

The cREMaG database [19] was used for in silico identification of molecular factors involved in the transcriptional control of the gene expression networks revealed in the present study. We found significant overrepresentation of SRE (serum-response elements, 4-fold enrichment; $\mathrm{P}<0.01$ ) and CRE (cAMP response elements, 3.8-fold enrichment, $\mathrm{P}<0.05$ ) in the promoter regions of genes from network $\alpha$. These elements are potential binding sites for the transcriptional factors SRF (e.g. in Egr1 and $A r c$ ) and CREB1 (e.g. in Dusp1 and Fosl2). Significant over-representation of GRE (glucocorticoid-response elements, 4.3-fold enrichment, $\mathrm{P}<0.01)$ on promoter regions of genes from network $\beta$ (e.g. in $T s c 22 d 3$ and $P d k 4$ ) was observed. Gene network $\gamma$ showed significant enrichment of binding sites for transcriptional factor NFYA (5.8-fold enrichment, $\mathrm{P}<0.01$ ). Two examples of genes with conserved binding sites for NFYA (regulatory subunit for NF-Y complex) are Per1 and Mtor.

\section{Transcript stability of drug-responsive genes}

Transcript stability is related to function of the transcribed protein [20]. Our analysis reveals substantial differences in the half-lives of mRNAs belonging to the $\alpha$ and $\beta$ networks. Gene expression network $\alpha$ contains genes with a short mRNA half-life (median $=2.9 \mathrm{~h}$ ), including very short-lived transcripts $(<2 \mathrm{~h}$ half-life: Gadd45g, Fos and Egr2). In contrast, network $\beta$ includes transcripts with significantly longer (median: $8.7 \mathrm{~h}$ ) halflives (> $20 \mathrm{~h}$ in the case of Sult1a1 and Itgad). Wholegenome screening indicated that genes with low mRNA stability are frequently involved in regulation of intracellular signaling, while long-lived transcripts have a role in cell metabolism [20]. The median half-life of transcripts from network $\gamma$ was $6.9 \mathrm{~h}$, i.e. not significantly different from the median of $5.6 \mathrm{~h}$ for the whole transcriptome.

\section{Functional classification of drug-responsive genes}

To characterize the transcriptional representation of biological processes, a list of genes from each gene expression network was analyzed using GO (Gene Ontology). Functional clusters of transcripts connected with protein MAP kinase phosphatase activity (81-fold enrichment,
$\mathrm{P}=2.4 \times 10^{-9}$; e.g., Dusp1 and Dusp4), rhythmic processes (7.2-fold, $\mathrm{P}=2.3 \times 10^{-3}$; e.g., Egr2 and Per2) and transcriptional regulator activity (2.8-fold, $\mathrm{P}=6.7 \times 10^{-5}$; e.g., Sertad1 and Atf3) were over-represented among genes from network $\alpha$. The group of genes from network $\beta$ was enriched in transcripts involved in lipid metabolism (11.5-fold, $\mathrm{P}=2.2 \times 10^{-3}$; e.g., Adipor2 and Pnpla2) and formation of adherens junctions (13.6-fold, $\mathrm{P}=1.3 \times 10^{-3}$; e.g., Dlg5 and Synm), whereas, analysis of the novel network $\gamma$ revealed the enrichment of genes connected to cell projection organization (4.7-fold, $\mathrm{P}=8.5 \times 10^{-3}$; e.g., Lst1 and Cnp). A detailed description of the results of GO classification is included in Additional file 6.

We did not find transcriptional regulation of genes coding main targets for psychotropic drugs, as for example dopamine receptors Drd2 and Drd1a or serotonin transporter Slc6a4. It is possible that promoters of these genes are not directly activated in response to the ligand binding.

\section{Canonical pathways analysis}

A canonical pathways analysis was performed to investigate the functional characteristics between drugregulated genes. To increase resolution of the analysis an extended list of transcripts was used (872 transcripts at $<5 \%$ FDR). Genes were assigned to the networks according to drug-induced profiles of alterations in expression (Additional files 1 and 5). The canonical pathways analysis using the Pathways-Express identified significant biological functions altered differentially by the psychotropic drugs at the statistical threshold of $\mathrm{P}<0.05$. The Additional file 7 contains a list of biological pathways for each drug-regulated transcriptional network. The list of pathways for gene expression network $\alpha$ includes neuroplasticity-related signaling cascades MAPK and ErbB. The network $\beta$ contains genes involved in the control of cellular metabolism via glucose regulation by adipocytokine and PPARG molecular pathways. The $\gamma$ network proved to be enriched in genes involved in regulation of circadian rhythm and mTOR signaling pathways. Additional file 8: Figure S8 shows examples of canonical pathways enriched between drug-responsive genes (Additional file 8).

\section{The examples of drug-regulated transcriptional profiles}

We selected genes with expression patterns representative for the identified drug-responsive transcriptional networks (Figure 3). In general, transcripts from network $\alpha$ reveal remarkable correlation in expression profile, but we also found drug-dependent diversity between particular genes.

The expression of Areg is induced by psychostimulants and tranylcypromine administration. The profile of Areg expression suggests that an increase in dopaminergic transmission may be directly involved in drug-induced 
regulation of this gene. Moreover, the time-course of alterations in Areg expression corresponds to pharmacokinetic properties of the drugs: we observed a strong increase in the mRNA abundance of Areg $1 \mathrm{~h}$ after injection of cocaine, $2 \mathrm{~h}$ after methamphetamine and $4 \mathrm{~h}$ after tranylcypromine. Npas 4 is induced by these three drugs in the same direction as Areg, but unlike Areg, Npas4 expression is also induced by opioids and inhibited by diazepam, atypical neuroleptics as well as antidepressants that antagonize 5-HT2 receptors. Other examples of genes with slightly different profiles are Egr2 and Arc, with expression induced by haloperidol and buspirone as well as Dusp1 and Fos, induced by haloperidol and mianserin (www.genes2mind.org).

Drug-induced network $\beta$ reveals more homogenous pattern of transcriptional alterations. Genes from this network showed the largest alterations (up to 6-fold vs. saline control group) in expression $4 \mathrm{~h}$ after administration of mianserin and tranylcypromine. Example gene $C d k n 1 a$ is activated to a different degree by all the psychotropic drugs, except for imipramine, diazepam and hydroxyzine.

Network $\gamma$ exhibits a pattern of gene expression changes that is connected to pharmacological properties of the drugs. Transcriptional activation of Cirbp is limited to mianserin, risperidone and clozapine treatment while opioids and psychostimulants seem to inhibit the expression of this gene and other network $\gamma$ genes (e.g., Trove 2 and Mrpl15).

\section{Prediction of drug-target interactions from gene expression profiling}

The comparison of gene expression profiles has been recently used as a tool for prediction of therapeutic properties of drugs [21-23]. Our molecular classification of psychotropic drugs indicated an interesting profile of tianeptine. Tianeptine is a tricyclic antidepressant whose mechanism of action is still not clear [24]. Here, a linear model, based on the level of gene expression alterations induced in the striatum by drugs with well-known pharmacological properties (Figure 5A), was used in an attempt to predict tianeptine's molecular mechanism(s) of action. The matrix of interactions between 14 psychotropic drugs and 13 neuropharmacological mechanisms was constructed on the basis of data in the PDSP $\mathrm{Ki}$ database [25]. Levels of modulation by tianeptine were predicted for each of the mechanisms. This analysis revealed that the transcriptional effects of tianeptine may involve increased activity of noradrenaline, serotonin and dopamine neurotransmission (Figure 5B).

\section{Monoaminergic action of tianeptine}

Further, in situ hybridization was used to examine the anatomical distribution of drug-induced alterations in the expression of two neuroplasticity-related genes following exposure of mice to tianeptine and two other antidepressants, tranylcypromine and mianserin. Patterns of tianeptine-induced expression of Arc and Egrl in the forebrain proved similar to those produced by tranylcypromine, an inhibitor of monoamine oxidase that increases the concentrations of all monoamine neurotransmitters; both drugs induced Arc and Egr1 transcription in the striatum and neocortex (Figure 5C). In contrast, mianserin, which affects levels of noradrenaline, but not of dopamine or serotonin, produced different effects; these included downregulation of Arc and Egr1 transcripts in the striatum. According to these profiles, we predicted that tianeptine, like other monoamine stimulants, may have a positive reinforcing effect in animals. This prediction was confirmed in the conditioned place preference test in which we observed a significant increase in time spent in the environmental context associated with tianeptine administration $(\mathrm{P}<0.01$, t-test) (Figure 5D). Thus, both the patterns of drug-induced gene expression and the behavioral data support the conclusion that tianeptine acts as a positive modulator of monoaminergic neurotransmission.

\section{Discussion}

The profile of drug-induced gene expression in the brain is determined by activity of different neurotransmiter systems and response of various types of cells. To unravel complexity of this profile we designed a detailed time-course gene expression study for eighteen psychotropic drugs belonging to all the major clinical classes. The previously published large-scale gene expression analyses were focused on a single drug [26,27], drugs from one clinical class [28,29] or marker genes [30,31]. Transcriptome alterations induced in the brain by buspirone, bupropione, hydroxyzine or tianeptine were not analyzed so far. The study involved extraction of a pool of approximately 1000 transcripts that are regulated by psychotropic drugs. Differential transcription of different subsets of genes from this pool was observed during the first few hours after drug administration; 90\% of the affected transcripts were up-regulated and the remaining were inhibited. Interestingly, the majority of drug-induced transcriptional alterations dissipated within 8 hours of treatment, indicating that drug-induced changes of mRNA abundance are transient. We suppose that they are then rapidly followed by protein expression and these proteomic alterations translate short-lived transcriptional drug effects into lasting structural modifications of the brain; further, we suggest that chronic drug treatment leads to accumulation of drug-induced plastic alterations that eventually become manifest as therapeutic effects. 


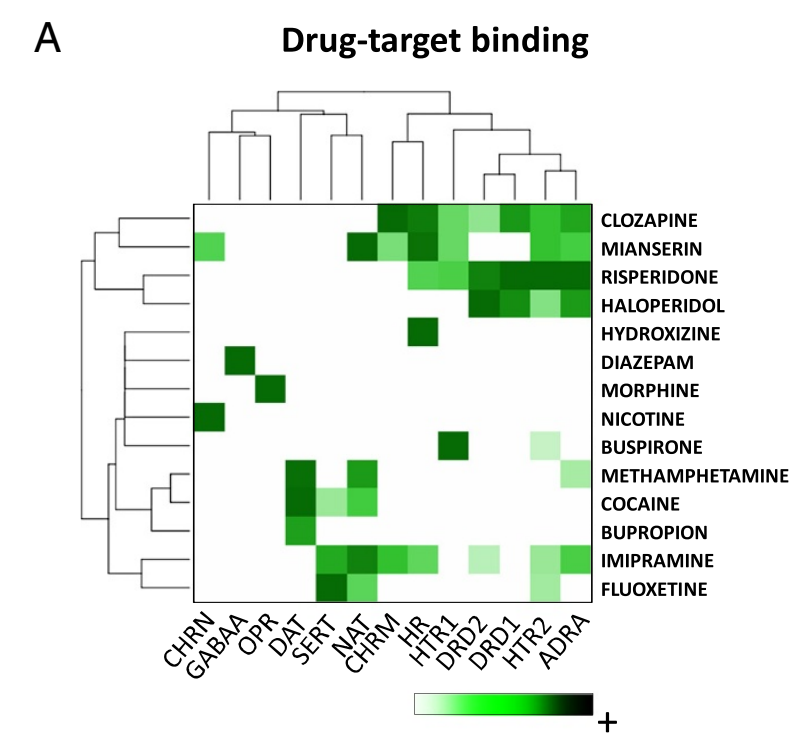

C in situ hybridization

\section{B Prediction of tianeptine targets}

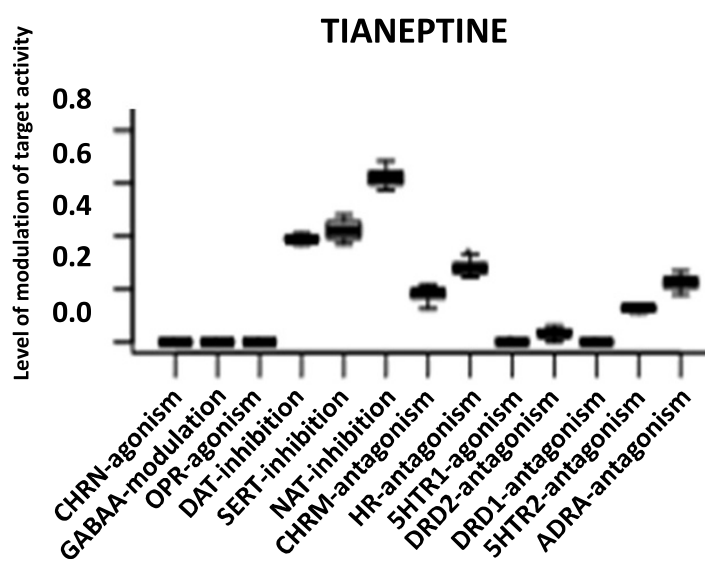

D

\section{Conditioned place preference}
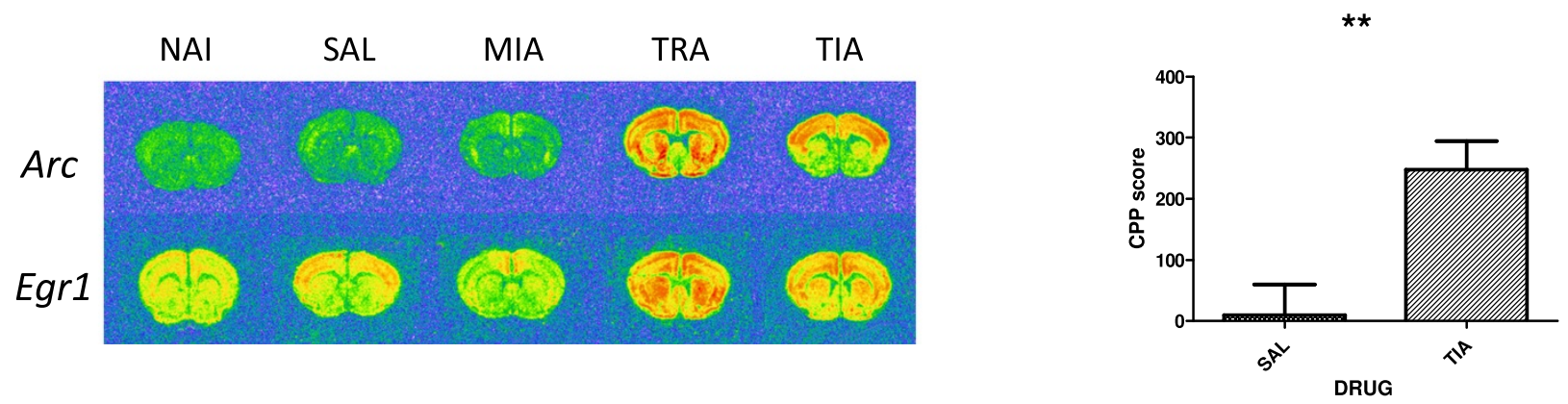

Figure 5 Prediction of tianeptine targets by gene expression profiling. A matrix of drug-target binding interactions from the PDSP Ki database (A). The mechanisms of tianeptine action predicted from expression profiles of the transcripts most sensitive to the analyzed pharmacological mechanisms (B). Brain distribution of tianeptine-induced gene expression alterations of Arc and Egr1 and (C). Rewarding properties of tianeptine in the conditioned place preference test. Scores are expressed as means + standard error of the mean (t-test, $\left.{ }^{* *} \mathrm{P}<0.01\right)$ (D).

This study was limited to transcriptional mechanisms activated in response to acute drug administration. The effects of psychoactive drugs such as anti-psychotic action, mood normalization, tolerance or addiction require repeated treatment. We have recently investigated gene expression changes at several time-points after chronic administration of heroin or methamphetamine to associate drug-induced molecular changes with long-term behavioral adaptations e [32]. In that work we found that effects of chronic treatment share transcriptional alterations with single administration, as for example regulation of glucocorticoid-dependent (Plin4 and Fkbp5) or circadian rhythm-regulated genes (Per1 or Per2). However, there were no direct correlations between transcriptional and behavioral effects of the drugs as well as no significant changes in gene expression profile after a period of withdrawal. We conclude that psychoactive drugs induce transient transcriptional program that may initiate neuroplastic alterations, but does not trigger long-term alteration in mRNA abundance levels in mature differentiated brain cells.

Bioinformatic analysis revealed that the transcriptional response to the psychotropic drugs tested fall into three major groups of co-regulated genes. The largest gene network, $\alpha$, contains genes previously defined as being activity-dependent. The observed alterations in expression of genes belonging to the network $\alpha$ correspond well to drug effects on neuronal activity (e.g. activation by cocaine and inhibition by diazepam); expression of genes in this network is known to depend on an interplay between the transcriptional factors CREB and SRF [33-35]. The gene network $\alpha$ includes a number of neuroplasticity-related transcriptional factors (e.g. Npas4, Egr1 and Fosb) as well as other regulators of brain 
plasticity (e.g. Arc and Homer1) [36-39]. Moreover, some network $\alpha$ genes are involved in MAP kinase signal transduction pathway (e.g. Dusp1 and Dusp6) which plays a pivotal role in various forms of long-lasting neuroplasticity $[40,41]$. The network $\alpha$ also contains novel genes (e.g. transcripts related to ErbB receptors signaling pathway Ddit4, developmental neuronal death Sertad1 or a modulator of Wnt and Fgf signaling pathways Shisa2) [42,43]. These genes deserve further functional characterization with respect to drug effects. All network $\alpha$ genes were shown to be expressed in neurons and their mRNAs were found to have relatively short half-lives. Several lines of evidence indicate that the expression of genes belonging to network $\alpha$ is involved in the initiation of plastic alterations and long-term modulation of neuronal signaling and the diverse functions of these genes indicate that psychotropic drugs activate control points for multiple intracellular pathways [44]. Accordingly, we suggest that, at the transcriptional level, brain plasticity is regulated through expression of molecular switches rather than of all components of neuroplasticity-related pathways.

Another network identified $(\beta)$ is strongly enriched in genes that are expressed predominantly in astrocytes and glucocorticoid response elements (GRE) in their promoter regions are overrepresented. However, while the collective function of network $\beta$ genes in astrocytes remains unknown, genes from this group are implicated in glucose metabolism e.g. Pdk4 and glucose transport e. g. Slc2a1 as well as other metabolic processes; in addition, Sult1a1 is involved in sulfate conjugation of neurotransmitters and certain xenobiotics and $X d h$ plays a role in the oxidative metabolism of purines [45-48]. The network $\beta$ is enriched for genes related to adipocytokine signaling pathway. This molecular cascade is an important regulator of energy intake and metabolic rate [49]. It thus appears that glial cells use expression of network $\beta$ genes to activate a set of metabolic control points and therefore, to support the functional responses of neurons to psychotropic drugs. The relatively long half-lives of the mRNAs generated from these genes most likely contribute to the regulation of neural cell metabolism [20]; interestingly, patients with affective disorders often display altered brain metabolism [50]. Glucocorticoids are key regulators of cellular metabolism and their dysregulated secretion is found in several psychiatric disorders [51]; in major depression, antidepressant actions are usually first seen only after glucocorticoid secretion has been normalized [52]. Thus, activation of glucocorticoid-dependent genes following psychotropic drug treatment may represent restoration of homeostatic control of brain metabolism.

The third psychotropic drug-inducible network, $\gamma$, that emerged from this study includes genes involved in the organization of cell projections (e.g. Lst1, Cnp) and the mTOR pathway (e.g. Mtor, Tsc1) [53-55]. Evolving evidence implicates the mTOR pathway in dendrite arborization and spine morphology [56]. Network $\gamma$ may therefore serve to switch on multiple control points for morphological alterations in nerve cells. Our results indicate that expression of this network in the striatum may depend on serotonin signaling, specifically the 5HT2 receptor. Thus, gene network $\gamma$ may be involved in the mediation of the long-lasting effects of 5-HT2 antagonist antipsychotic drugs on the cellular level. Moreover, the 5-HT2 blockade-dependent expression of network $\gamma$ in the striatum that separates haloperidol from risperidone may be useful as a transcriptional marker for atypical neuroleptics.

The current Anatomical Therapeutic Chemical (ATC) and World Health Organization (WHO) classification of psychotropic drugs is based on their clinical effectiveness. As shown by the present work, comparison of gene expression profiles can clearly distinguish between atypical antipsychotics, opioids and psychostimulants. Moreover, the three anxiolytic drugs studied here show relatively similar genomic profiles despite the different mechanisms associated with their actions. Interestingly, these anxiolytics and the antidepressant imipramine share a common expression profile and imipramine can act efficiently to reduce anxiety [57]. On the other hand, the molecular profile of mianserin differs markedly from that of imipramine while being similar to that of the atypical antipsychotics clozapine and risperidone; this may reflect the fact that all of these drugs can modulate serotonergic activity. The potential utility of the presently-described approach to distinguish between the two classes of antipsychotics is further illustrated by the finding that the typical antipsychotic haloperidol has a similar molecular profile to that of psychostimulant drugs. This most likely results from the propensity of all these drugs to upregulate activity-dependent genes in the striatum. It is important to note, however, that haloperidol and psychostimulants induce these genes in different neuronal populations and via different pharmacological mechanisms [58]. Another observation from the present analysis is that drugs which trigger large increases in striatal dopamine and norepinephrine levels induce similar expression profiles (cocaine and methamphetamine, tranylcypromine).

In general, antidepressants proved to be highly heterogeneous with respect to activation of molecular networks. This diversity reflects their diverse pharmacological and neurobiological mechanisms of action [12], as well as significant differences in the efficacy of individual compounds in the treatment of different forms of depression [2,59]. Based on the present analysis of transcriptional profiles, it would appear that mianserin would be a highly effective treatment for psychotic depression, imipramine for anxietydepressive disorders, and tranylcypromine for depression 
associated with anhedonia. The broad gene expression profile of fluoxetine indicates that it would be a suitable firstline treatment [60].

The prediction of drug properties based on the pattern of gene expression alterations need not exactly correspond to the therapeutic profile. To form multidimensional profile of a drug or novel psychoactive compound the results of molecular analysis should be combined with binding profile and behavioral response [61,62]. The pharmacological mechanisms of action of the tricyclic drug tianeptine, indicated for depression, are not fully understood. The present genomic profiling approach appears to have the potential to identify neuronal targets for drugs with unknown mechanisms of action as well as for experimental compounds [63-65]. Until now, tianeptine has been thought to act by either enhancing serotonin reuptake, modulating glutamatergic transmission and/or counteracting maladaptive stress-induced neuroplasticity $[24,66]$; however, none of these mechanisms has been fully validated. The present study revealed that the transcriptional effects of tianeptine may result from a blockade of norepinephrine, serotonin and dopamine transporters; in this respect, tianpetine shares some of the dopaminergic and noradrenergic properties with its predecessor amineptine [67]. Supporting the view that tianeptine acts primarily by modulating monoaminergic function are clinical findings that the tianeptine, has moderate addictive potential comparable to diazepam [68] as well as the presently observed pattern of tianeptine-induced expression of activitydependent genes. Importantly, the lack of tianeptinebinding molecular targets suggests that the drug indirectly influences monoamine levels [69]. The transcriptional profile of tianeptine is not necessarily in conflict with the previously proposed mechanisms of its action as positive effects of tianeptine on both glutamatergic transmission and neuroplasticity might be indirect. However, our results suggest a change in tianeptine status from a drug acting through unknown mechanisms to an antidepressant with remarkable ability to modulate all three monoamine systems. Compounds with such activity profile have been recently proposed as likely to form the basis for the development of the next generation of antidepressant drugs [70].

\section{Conclusions}

Psychotropic drugs conventionally classified as antidepressants, antipsychotics, anxiolytics, psychostimulants and opioids regulate expression of three major gene expression networks implicated in the control of neuronal signaling, brain metabolism and organization of cell projections. The patterns of drug-induced gene networks revealed here offer new valuable markers of pharmacological activation of diverse neurobiological processes and systems. In particular, the present study provides novel insights into the mechanisms through which tianeptine might exert its antidepressant action.

\section{Methods}

Animals

Adult male (8 to 10 weeks old) C57BL/6 J inbred mice (Jackson Laboratory, Bar Harbor, ME, USA) were housed 6 to 10 per cage under a 12-h dark/light cycle with free access to food and water. Animals weighing 20 to $30 \mathrm{~g}$ were used throughout the experiments. The animal protocols were approved by the local Bioethics Commission at the Institute of Pharmacology PAS.

\section{Drug treatment}

Mice were injected i.p. (vol. $10 \mathrm{ml} / \mathrm{kg}$ ) with drugs listed in Table 1 . Then animals were sacrificed by decapitation $1,2,4$ or $8 \mathrm{~h}$ after a single injection along with the appropriate vehicle and naïve control groups (6 animals per each drug-treated and control group). Risperidone, haloperidol, clozapine and diazepam were suspended in 1\% Tween 80 solution (Sigma-Aldrich, St. Louis, MO, USA); other drugs were dissolved in saline. The effective doses of psychotropic drugs were based on the literature, particular attention being payed to their pharmacological effects in C57BL/6 J mice [71-79]. The doses were selected to provide reasonable comparison of drugs effects on the molecular level.

\section{Tissue collection and RNA isolation}

Samples containing the rostral part of the caudate putamen and the nucleus accumbens, referred to hereafter as the striatum, were collected. The dissection procedure was performed as previously described [80]. In addition, tissue samples containing frontal cortex, amygdalae and hippocampus were frozen in order to allow future experiments. Tissue samples were placed in RNAlater reagent (Qiagen Inc., Valencia, CA, USA) and preserved at $-70^{\circ} \mathrm{C}$. Samples were homogenized in $1 \mathrm{ml}$ Trizol reagent (Invitrogen, Carlsbad, CA, USA). RNA was isolated following the manufacturer's protocol and further purified using the RNeasy Mini Kit (Qiagen Inc.). The total RNA concentration was measured using a ND-1000 Spectrometer (NanoDrop Technologies Inc., Montchanin, DE, USA). RNA quality was determined using an Agilent Bioanalyzer 2100 (Agilent, Palo Alto, CA, USA).

\section{Microarray hybridization}

A starting amount of $200 \mathrm{ng}$ high-quality total RNA (pooled 1:1 from two animals) was used to generate cDNA and cRNA with the Illumina TotalPrep RNA Amplification Kit (Illumina Inc., San Diego, CA, USA). The obtained cDNA served as a template for in vitro transcription with T7 RNA polymerase and biotin UTP 
to generate multiple copies of biotinylated cRNA. Each cRNA sample $(1.5 \mu \mathrm{g})$ was hybridized overnight to MouseWG-6 BeadChip array (Illumina); subsequently, chips were washed, dried and scanned with the BeadArray Reader (Illumina). Raw microarray data were generated using BeadStudio v3.0 (Illumina). A total of 108 Illumina MouseWG-6 v1.1 and 216 Illumina MouseWG-6 v2 microarrays were used (three independent arrays per group). Samples from 2 mice were pooled per microarray, 3 biological replicates were used per time-point and 12 arrays per each drug. To provide an overall appropriately balanced dataset, treatment group samples were distributed between array plates and hybridization batches.

\section{Microarray data analysis}

Analysis and quality control of 324 microarrays were performed using BeadArray $\mathrm{R}$ package v1.10.0. After background subtraction, data was normalized using quantile normalization and then log2-transformed. Results were standardized to reduce the effect of hybridization batches using $\mathrm{z}$-score transformation. All the experiments were planned and performed to allow direct comparison of a relatively large number of psychoactive drugs. Gene cross-annotation between the two versions of Illumina microarrays was performed automatically.

All statistical analyses were performed in R software version 2.11.1 [81]. There were no significant differences in mRNA abundance levels between the batches of vehicletreated animals (saline as well as Tween 80) after correction for multiple testing. Therefore, for drug comparison all control groups were combined together. Two-way ANOVA with fixed effects for drug factor $(\mathrm{df}=19)$, time factor $(\mathrm{df}=3)$ and interaction $(\mathrm{df}=57)$ was followed by appropriate correction for multiple testing (using the Bonferroni or Benjamini-Hochberg procedures).

The genes2mind gene selection score (implemented on www.genes 2 mind.org) was computed as follows:

$$
\text { score }=\frac{\left(10 *\left(-\log _{2} p_{i j}\right) * \log _{2}\left(\text { fold }_{i j}+1\right) * \text { foldmean }_{i}\right)}{\text { folds }_{i}}
$$

The variables described: $\mathrm{i}$ - drug, $\mathrm{j}$ - time-point, $\mathrm{p}$ - P value obtained from Student's t test, fold - fold of change compared to saline control, foldmean - mean fold change from the four experimental time-points and foldsd - standard deviation of fold values from the four time-points. The data integration system was based on MySQL in the data layer, Java in the logic layer and AJAX (GWT) in the presentation layer. Published databases $[18,19,82]$ were used to check cell-type enrichment, mRNA half-life and to control for overrepresentation of TFBSs of genes $[18,19,82]$. The functional annotation analysis tool DAVID 2008 was used to identify over-represented ontologic groups among the gene expression patterns [83]. The list of transcripts represented on the Illumina Mouse WG-6 microarray was used as a background list. Over-represented GO terms were defined as having at least three transcripts and $\mathrm{P}<0.05$ under Fisher's exact test. The automated functional profiling of drug-regulated genes was performed using the Pathways-Express online tool with default parameters [84].

\section{Identification of co-expressed gene networks}

Spearman correlations were calculated for all pairs of gene expression profiles. A co-expression tree that grouped transcripts with the most similar expression profiles was built using correlation coefficients and a minimal spanning tree algorithm. Visual representation of the data was obtained using the sfdp algorithm from the graphviz R library. Clusters of co-expressed genes were identified using the single-linkage clustering method. Walk-length on the co-expression tree (number of edges separating corresponding transcripts) was used as the distance metric for clustering. The top 300 drug-regulated transcripts were selected (at genes2mind score $>1.8$ ) for clustering. An arbitrary cutoff value (internode distance $=4$ ) was selected to dissect major drug-inducible gene expression networks.

\section{Model-based inference of pharmacological mechanisms}

The pharmacological mechanisms underlying the observed gene expression alterations were transformed into a linear model. Transcriptional effects were modeled as a product of two factors, as follows:

$$
E_{\text {transcript }}=\sum_{\text {mech }} A_{m e c h}^{\text {transcript }} \cdot B_{d r u g}^{\text {mech }}
$$

Variable A described the sensitivity of transcript abundance to activation levels of a given pharmacological mechanism. The strength of drug-target interaction was represented by the binding parameter $\mathrm{B}$. Its values were based on binding constants found in the PDSP Ki database [25]. The binding matrix contained data on 14 drugs that act through at least one of the 13 pharmacological targets. Together with experimental expression levels, the binding data allowed for the estimation of sensitivity parameters A through a least squares fit. The theoretical model was used to infer the possible mechanisms of tianeptine action. The response matrix A was reduced by finding the 50 most sensitive transcripts for each tested pharmacological mechanism. After removal of duplicates, 350 transcripts were selected for further analysis and their responses to tianeptine were represented by expression vector E'. Together with reduced response matrix $\mathrm{A}^{\prime}, \mathrm{E}^{\prime}$ was used in a least squares fit to theoretically predicted tianeptine-induced activation of 
pharmacological targets. The accuracy of the model was tested by prediction of tranylcypromine mechanism of action (Additional file 9).

\section{In situ hybridization}

The frozen brains were cut into $12 \mu \mathrm{m}$-thick coronal sections on a cryostat microtome CM 3050S (Leica Microsystems, Germany), and the sections were thawmounted on gelatin-chrome alum-coated slides and processed for in situ hybridization. The hybridization procedure was performed as previously described [85]. Briefly, the sections were fixed with $4 \%$ paraformaldehyde, washed in PBS and acetylated by incubation with $0.25 \%$ acetic anhydrite (in $0.1 \mathrm{M}$ triethanolamine and $0.9 \%$ sodium chloride). The sections were dehydrated using increasing concentrations of ethanol (70 to 100\%), treated with chloroform for 5 minutes and rehydrated with decreasing concentrations of ethanol. The sections were hybridized for $15 \mathrm{~h}$ at $37^{\circ} \mathrm{C}$ with oligonucleotide probes complementary to Arc and Egr1 cDNA. The probes were labeled with 35S-dATP by the 3 '-tailing reaction using terminal transferase (MBI Fermentas, Vilnius, Lithuania). After hybridization, the slices were washed three times for 20 minutes with $1 \times \mathrm{SSC} / 50 \%$ formamide at $40^{\circ} \mathrm{C}$ and twice for 50 minutes with $1 \times$ SSC at room temperature. Then, the slices were dried and exposed to phosphorimager plates (Fujifilm, Tokyo, Japan) for 5 days. The hybridization signal was digitized using a Fujifilm BAS-5000 phosphorimager and Image Reader software (Fujifilm).

\section{Conditioned place preference}

CPP tests were performed using an unbiased procedure in a three-arm apparatus. The experiment consisted of the following phases separated by $24 \mathrm{~h}$ : pre-conditioning test (day 0), conditioning with a tianeptine dose of $20 \mathrm{mg} / \mathrm{kg}$ (days 1, 3, 5), conditioning with saline (days 2, $4,6)$ and post-conditioning test (day 7). The CPP score was defined as the time spent in the drug-paired compartment on day 7 minus the time spent in the same compartment in the preconditioning phase on day 0 . The scores were expressed as means with the standard error of the mean.

\section{URLs}

Bioinformatic platforms: genes2mind, http://genes2mind. org; cREMaG database, http://cremag.org; PDSP Ki database, http://pdsp.med.unc.edu.

\section{Accession codes}

Microarray data are available in the NCBI Gene Expression Omnibus (GEO) under accession numbers GEO: GSE15774, GSE48951 and GSE48954.

\section{Additional files}

\begin{abstract}
Additional file 1: A table listing the results of the two-way ANOVA for drug treatment factor (followed by Bonferroni or FDR corrections for multiple tests). For drug-regulated transcripts genes 2 mind scores and gene network associations are provided. The second sheet contains lists of the genes from the three major gene expression networks $a, \beta$ and $\gamma$.
\end{abstract}

Additional file 2: ANOVA results of gene expression profiling of drug effects in mouse striatum. A figure presenting the relationship between the number of true positive results and the proportion of false positives for drug factor in ANOVA.

Additional file 3: A table listing the comparison of transcriptional effects of the tested psychotropic drugs. The table contains the number of regulated transcripts (genes 2 mind score $>10$ ) at each timepoint of the experiment (obtained using the genes 2 mind gene selection module).

Additional file 4: A figure showing a minimal spanning tree of the whole-transcriptome, based on correlation of gene expression profiles. Each node represents one transcript (an example branch with 4 transcripts was presented on the right). The internode distance is proportional to the Spearman correlation of the expression levels of two transcripts. The top 300 drug-responsive genes are depicted by red color (defined by genes 2 mind score using the four time-points).

Additional file 5: A figure showing hierarchical clustering of druginduced gene expression alterations in the mouse striatum. Microarray results are shown as a heat map and include 872 transcripts with a significance (FDR $<5 \%$ ) obtained from two-way analysis of variance of the drug factor. Colored rectangles represent transcript abundance 1, 2, 4 and $8 \mathrm{~h}$ after injection of the drug indicated above. The intensity of the color is proportional to the standardized values from each microarray. Drug-responsive gene networks were denoted on the right.

Additional file 6: A table listing the complete results of the GO analysis presented in the manuscript. The analyses were performed on lists of genes that correspond to networks $a, \beta$ and $\gamma$ (results are presented in separate sheets). The analyzed genes are listed in Additional file 1.

Additional file 7: A table listing the complete results of the canonical pathways analysis presented in the manuscript. The analyses were performed on extended (FDR $<5 \%$ ) lists of genes that correspond to networks $a, \beta$ and $\gamma$ (results are presented in separate sheets). The analyzed genes are listed in Additional file 1.

Additional file 8: A figure showing examples of canonical biological pathways regulated by psychotropic drugs. The analyses were performed on extended (FDR $<5 \%$ ) lists of genes that correspond to networks patterns $\alpha, \beta$ and $\gamma$. The pathways were created based on KEGG database using the Pathways-Express online tool. Drug-responsive genes were indicated using yellow color.

Additional file 9: The mechanisms of tranylcypromine action predicted from expression profiles of the transcripts most sensitive to the analyzed pharmacological mechanisms (for details please see Methods section).

\section{Abbreviations}

PCA: Principal component analysis; SRE: Serum-response element; CRE: CAMP response element; GRE: Glucocorticoid-response element; GO: Gene ontology; TFBS: Transcription factor binding site; CPP: Conditioned place preference.

\section{Competing interests}

The authors declare that they have no competing financial interests.

\section{Authors' contributions}

MK designed the study, interpreted the results and drafted the manuscript. MP, WM and JD performed statistical analyses and developed bioinformatics tools. KS conducted behavioral testing. BZ was responsible for in situ 
hybridization experiments. RP coordinated the study and reviewed the manuscript. All authors read and approved the final manuscript.

\section{Acknowledgments}

This work was supported by Polish MSHE grants NN405 274137, IUVENTUS Plus and POIG De-Me-Ter 3.1. We thank Osborne Almeida for helpful suggestions and critical comments on the manuscript.

Received: 24 June 2013 Accepted: 29 August 2013

Published: 8 September 2013

\section{References}

1. Wittchen HU, Jacobi F, Rehm J, Gustavsson A, Svensson M, Jonsson B, Olesen J, Allgulander C, Alonso J, Faravelli C, et al: The size and burden of mental disorders and other disorders of the brain in Europe 2010. Eur Neuropsychopharmacol 2011, 21(9):655-679.

2. Simon GE, Perlis RH: Personalized medicine for depression: can we match patients with treatments? Am J Psychiatry 2010, 167(12):1445-1455.

3. Goto Y, Yang CR, Otani S: Functional and dysfunctional synaptic plasticity in prefrontal cortex: roles in psychiatric disorders. Biol Psychiatry 2010, 67(3):199-207.

4. Christoffel DJ, Golden SA, Russo SJ: Structural and synaptic plasticity in stress-related disorders. Rev Neurosci 2011, 22(5):535-549.

5. Vidal R, Pilar-Cuellar F, dos Anjos S, Linge R, Treceno B, Vargas VI, RodriguezGaztelumendi A, Mostany R, Castro E, Diaz A, et al: New strategies in the development of antidepressants: towards the modulation of neuroplasticity pathways. Curr Pharm Des 2011, 17(5):521-533.

6. Luscher C, Malenka RC: Drug-evoked synaptic plasticity in addiction: from molecular changes to circuit remodeling. Neuron 2011, 69(4):650-663.

7. Nguyen PV, Abel T, Kandel ER: Requirement of a critical period of transcription for induction of a late phase of LTP. Science 1994, 265(5175):1104-1107.

8. McClung CA, Nestler EJ: Neuroplasticity mediated by altered gene expression. Neuropsychopharmacology 2008, 33(1):3-17.

9. Krishnan V, Nestler EJ: Linking molecules to mood: new insight into the biology of depression. Am J Psychiatry 2010, 167(11):1305-1320.

10. Mega MS, Cummings JL: Frontal-subcortical circuits and neuropsychiatric disorders. J Neuropsychiatry Clin Neurosci 1994, 6(4):358-370.

11. Hyman SE, Malenka RC, Nestler EJ: Neural mechanisms of addiction: the role of reward-related learning and memory. Annu Rev Neurosci 2006, 29:565-598.

12. Westenberg HG: Pharmacology of antidepressants: selectivity or multiplicity? J Clin Psychiatry 1999, 60(Suppl 17):4-8. discussion 46-48.

13. Lopez-Munoz F, Alamo C: Monoaminergic neurotransmission: the history of the discovery of antidepressants from 1950s until today. Curr Pharm Des 2009, 15(14):1563-1586.

14. Konradi C, Heckers S: Antipsychotic drugs and neuroplasticity: insights into the treatment and neurobiology of schizophrenia. Biol Psychiatry 2001, 50(10):729-742.

15. Shiflett MW, Balleine BW: Molecular substrates of action control in corticostriatal circuits. Prog Neurobiol 2011, 95(1):1-13.

16. Strand AD, Aragaki AK, Baquet ZC, Hodges A, Cunningham P, Holmans $P$, Jones KR, Jones L, Kooperberg C, Olson JM: Conservation of regional gene expression in mouse and human brain. PLOS Genet 2007, 3(4):e59.

17. Nestler EJ, Hyman SE: Animal models of neuropsychiatric disorders. Nature neuroscience 2010, 13(10):1161-1169.

18. Cahoy JD, Emery B, Kaushal A, Foo LC, Zamanian JL, Christopherson KS, Xing Y, Lubischer JL, Krieg PA, Krupenko SA, et al: A transcriptome database for astrocytes, neurons, and oligodendrocytes: a new resource for understanding brain development and function. J Neurosci 2008, 28(1):264-278

19. Piechota M, Korostynski M, Przewlocki R: Identification of cis-regulatory elements in the mammalian genome: the CREMaG database. PLoS One 2010, 5(8):e12465.

20. Schwanhausser B, Busse D, Li N, Dittmar G, Schuchhardt J, Wolf J, Chen W, Selbach M: Global quantification of mammalian gene expression control. Nature 2011, 473(7347):337-342.

21. Sirota M, Dudley JT, Kim J, Chiang AP, Morgan AA, Sweet-Cordero A, Sage J, Butte AJ: Discovery and preclinical validation of drug indications using compendia of public gene expression data. Sci Trans/ Med 2011, 3(96):96ra77.
22. Dudley JT, Sirota M, Shenoy M, Pai RK, Roedder S, Chiang AP, Morgan AA, Sarwal MM, Pasricha PJ, Butte AJ: Computational repositioning of the anticonvulsant topiramate for inflammatory bowel disease. Sci Trans/ Med 2011, 3(96):96ra76.

23. Lamb J, Crawford ED, Peck D, Modell JW, Blat IC, Wrobel MJ, Lerner J, Brunet JP, Subramanian A, Ross KN, et al: The Connectivity Map: using gene-expression signatures to connect small molecules, genes, and disease. Science 2006, 313(5795):1929-1935.

24. McEwen BS, Chattarji S, Diamond DM, Jay TM, Reagan LP, Svenningsson P, Fuchs E: The neurobiological properties of tianeptine (Stablon): from monoamine hypothesis to glutamatergic modulation. Mol Psychiatry 2010, 15(3):237-249.

25. Roth BL, Kroeze WK, Patel S, Lopez E: The Multiplicity of Serotonin Receptors: Uselessly diverse molecules or an embarrasment of riches? Neuroscientist 2000, 6:252-262.

26. Korostynski M, Piechota M, Kaminska D, Solecki W, Przewlocki R: Morphine effects on striatal transcriptome in mice. Genome Biol 2007, 8(6):R128.

27. Krasnova IN, Li SM, Wood WH, McCoy MT, Prabhu W, Becker KG, Katz JL, Cadet JL: Transcriptional responses to reinforcing effects of cocaine in the rat hippocampus and cortex. Genes Brain Behav 2008, 7(2):193-202.

28. MacDonald ML, Eaton ME, Dudman JT, Konradi C: Antipsychotic drugs elevate mRNA levels of presynaptic proteins in the frontal cortex of the rat. Biol Psychiatry 2005, 57(9):1041-1051.

29. Lee JH, Ko E, Kim YE, Min JY, Liu J, Kim Y, Shin M, Hong M, Bae H: Gene expression profile analysis of genes in rat hippocampus from antidepressant treated rats using DNA microarray. BMC Neurosci 2010, 11:152.

30. Sumner BE, Cruise LA, Slattery DA, Hill DR, Shahid M, Henry B: Testing the validity of c-fos expression profiling to aid the therapeutic classification of psychoactive drugs. Psychopharmacology (Berl) 2004, 171(3):306-321.

31. Nguyen TV, Kosofsky BE, Birnbaum R, Cohen BM, Hyman SE: Differential expression of c-fos and zif268 in rat striatum after haloperidol, clozapine, and amphetamine. Proc Natl Acad Sci USA 1992, 89(10):4270-4274.

32. Piechota M, Korostynski M, Sikora M, Golda S, Dzbek J, Przewlocki R: Common transcriptional effects in the mouse striatum following chronic treatment with heroin and methamphetamine. Genes Brain Behav 2012, 11(4):404-414

33. Miyashita T, Kubik S, Haghighi N, Steward O, Guzowski JF: Rapid activation of plasticity-associated gene transcription in hippocampal neurons provides a mechanism for encoding of one-trial experience. J Neurosci 2009, 29(4):898-906.

34. Benito $E$, Valor LM, Jimenez-Minchan M, Huber W, Barco A: cAMP response element-binding protein is a primary hub of activity-driven neuronal gene expression. J Neurosci 2011, 31(50):18237-18250.

35. Parkitna JR, Bilbao A, Rieker C, Engblom D, Piechota M, Nordheim A, Spanagel R, Schutz G: Loss of the serum response factor in the dopamine system leads to hyperactivity. FASEB J 2010, 24(7):2427-2435.

36. Ramamoorthi K, Fropf $R$, Belfort GM, Fitzmaurice HL, McKinney RM, Neve RL, Otto $T$, Lin $Y$ : Npas4 regulates a transcriptional program in $C A 3$ required for contextual memory formation. Science 2011, 334(6063):1669-1675.

37. Vialou V, Robison AJ, Laplant QC, Covington HE 3rd, Dietz DM, Ohnishi YN, Mouzon E, Rush AJ 3rd, Watts EL, Wallace DL, et al: DeltaFosB in brain reward circuits mediates resilience to stress and antidepressant responses. Nat Neurosci 2010, 13(6):745-752.

38. Jones MW, Errington ML, French PJ, Fine A, Bliss TV, Garel S, Charnay P, Bozon $B$, Laroche $S$, Davis $S$ : A requirement for the immediate early gene Zif268 in the expression of late LTP and long-term memories. Nat Neurosci 2001, 4(3):289-296.

39. Szumlinski KK, Dehoff MH, Kang SH, Frys KA, Lominac KD, Klugmann M, Rohrer J, Griffin W 3rd, Toda S, Champtiaux NP, et al: Homer proteins regulate sensitivity to cocaine. Neuron 2004, 43(3):401-413.

40. Sweatt JD: Mitogen-activated protein kinases in synaptic plasticity and memory. Curr Opin Neurobiol 2004, 14(3):311-317.

41. Duric V, Banasr M, Licznerski P, Schmidt HD, Stockmeier CA, Simen AA, Newton SS, Duman RS: A negative regulator of MAP kinase causes depressive behavior. Nat Med 2010, 16(11):1328-1332.

42. Hedge TA, Mason I: Expression of Shisa2, a modulator of both Wnt and Fgf signaling, in the chick embryo. Int J Dev Biol 2008, 52(1):81-85.

43. Biswas SC, Zhang Y, lyirhiaro G, Willett RT, Rodriguez Gonzalez Y, Cregan SP, Slack RS, Park DS, Greene LA: Sertad1 plays an essential role in 
developmental and pathological neuron death. J Neurosci 2010, 30(11):3973-3982.

44. Loebrich S, Nedivi E: The function of activity-regulated genes in the nervous system. Physiol Rev 2009, 89(4):1079-1103.

45. Jeoung NH, Wu P, Joshi MA, Jaskiewicz J, Bock CB, Depaoli-Roach AA, Harris RA: Role of pyruvate dehydrogenase kinase isoenzyme 4 (PDHK4) in glucose homoeostasis during starvation. Biochem J 2006, 397(3):417-425.

46. Chari M, Yang CS, Lam CK, Lee K, Mighiu P, Kokorovic A, Cheung GW, Lai TY, Wang PY, Lam TK: Glucose transporter-1 in the hypothalamic glial cells mediates glucose sensing to regulate glucose production in vivo. Diabetes 2011, 60(7):1901-1906.

47. Barnett AC, Tsvetanov S, Gamage N, Martin JL, Duggleby RG, McManus ME: Active site mutations and substrate inhibition in human sulfotransferase $1 \mathrm{~A} 1$ and 1A3. J Biol Chem 2004, 279(18):18799-18805.

48. Kudo M, Moteki T, Sasaki T, Konno Y, Ujiie S, Onose A, Mizugaki M, Ishikawa M, Hiratsuka M: Functional characterization of human xanthine oxidase allelic variants. Pharmacogenet Genomics 2008, 18(3):243-251.

49. Ahima RS, Qi Y, Singhal NS, Jackson MB, Scherer PE: Brain adipocytokine action and metabolic regulation. Diabetes 2006, 55(Suppl 2):S145-S154.

50. Moretti A, Gorini A, Villa RF: Affective disorders, antidepressant drugs and brain metabolism. Mol Psychiatry 2003, 8(9):773-785.

51. Steckler T, Holsboer F, Reul JM: Glucocorticoids and depression. Baillieres Best Pract Res Clin Endocrinol Metab 1999, 13(4):597-614.

52. Ising M, Horstmann S, Kloiber S, Lucae S, Binder EB, Kern N, Kunzel HE, Pfennig A, Uhr M, Holsboer F: Combined dexamethasone/corticotropin releasing hormone test predicts treatment response in major depression - a potential biomarker? Biol Psychiatry 2007, 62(1):47-54.

53. Raghunathan A, Sivakamasundari R, Wolenski J, Poddar R, Weissman SM: Functional analysis of B144/LST1: a gene in the tumor necrosis factor cluster that induces formation of long filopodia in eukaryotic cells. Exp Cell Res 2001, 268(2):230-244

54. Lee J, Gravel M, Zhang R, Thibault P, Braun PE: Process outgrowth in oligodendrocytes is mediated by CNP, a novel microtubule assembly myelin protein. J Cell Biol 2005, 170(4):661-673.

55. Hoeffer CA, Klann E: mTOR signaling: at the crossroads of plasticity, memory and disease. Trends Neurosci 2010, 33(2):67-75.

56. Jaworski J, Sheng M: The growing role of mTOR in neuronal development and plasticity. Molecular neurobiology 2006, 34(3):205-219.

57. Huh J, Goebert D, Takeshita J, Lu BY, Kang M: Treatment of generalized anxiety disorder: a comprehensive review of the literature for psychopharmacologic alternatives to newer antidepressants and benzodiazepines. Prim Care Companion CNS Disord 2011, 13(2). http://www.ncbi.nlm.nih.gov/pmc/articles/PMC3184575/.

58. Berretta S, Sachs Z, Graybiel AM: Cortically driven Fos induction in the striatum is amplified by local dopamine D2-class receptor blockade. Eur J Neurosci 1999, 11(12):4309-4319.

59. Ghaemi SN: Why antidepressants are not antidepressants: STEP-BD, STAR*D, and the return of neurotic depression. Bipolar Disord 2008, 10(8):957-968.

60. Furukawa TA, Akechi T, Shimodera S, Yamada M, Miki K, Watanabe N, Inagaki M, Yonemoto N: Strategic use of new generation antidepressants for depression: SUN $\left(\wedge \_\wedge\right) D$ study protocol. Trials 2011, 12:116.

61. Kafkafi N, Yekutieli D, Elmer Gl: A data mining approach to in vivo classification of psychopharmacological drugs. Neuropsychopharmacology 2009, 34(3):607-623.

62. Liu T, Lin Y, Wen $X$, Jorissen RN, Gilson MK: BDB: a web-accessible database of experimentally determined protein-ligand binding affinities. Nucleic Acids Res 2007, 35(Database issue):D198-201.

63. Levy SE: Microarray analysis in drug discovery: an uplifting view of depression. Sci STKE 2003, 2003(206):pe46.

64. Gunther EC, Stone DJ, Gerwien RW, Bento P, Heyes MP: Prediction of clinical drug efficacy by classification of drug-induced genomic expression profiles in vitro. Proc Natl Acad Sci USA 2003, 100(16):9608-9613.

65. Gunther EC, Stone DJ, Rothberg JM, Gerwien RW: A quantitative genomic expression analysis platform for multiplexed in vitro prediction of drug action. The pharmacogenomics journal 2005, 5(2):126-134.

66. Czeh B, Michaelis T, Watanabe T, Frahm J, de Biurrun G, van Kampen M, Bartolomucci A, Fuchs E: Stress-induced changes in cerebral metabolites, hippocampal volume, and cell proliferation are prevented by antidepressant treatment with tianeptine. Proc Natl Acad Sci USA 2001, 98(22):12796-12801.
67. Bonnet JJ, Chagraoui A, Protais P, Costentin J: Interactions of amineptine with the neuronal dopamine uptake system: neurochemical in vitro and in vivo studies. J Neural Transm 1987, 69(3-4):211-220.

68. Rouby F, Pradel V, Frauger E, Pauly V, Natali F, Reggio P, Thirion X, Micallef J: Assessment of abuse of tianeptine from a reimbursement database using 'doctor-shopping' as an indicator. Fundam Clin Pharmacol 2011, 26(2):286-294

69. Vaugeois JM, Corera AT, Deslandes A, Costentin J: Although chemically related to amineptine, the antidepressant tianeptine is not a dopamine uptake inhibitor. Pharmacol Biochem Behav 1999, 63(2):285-290.

70. Guiard BP, El Mansari M, Blier P: Prospect of a Dopamine Contribution in the Next Generation of Antidepressant Drugs: The Triple Reuptake Inhibitors. Curr Drug Targets 2009, 10(11):1069-1084.

71. Kulkarni SK, Dhir A: Effect of various classes of antidepressants in behavioral paradigms of despair. Prog Neuropsychopharmacol Biol Psychiatry 2007, 31(6):1248-1254.

72. Risbrough VB, Brodkin JD, Geyer MA: GABA-A and 5-HT1A receptor agonists block expression of fear-potentiated startle in mice. Neuropsychopharmacology 2003, 28(4):654-663.

73. Solich J, Palach P, Budziszewska B, Dziedzicka-Wasylewska M: Effect of two behavioral tests on corticosterone level in plasma of mice lacking the noradrenaline transporter. Pharmacol Rep 2008, 60(6):1008-1013.

74. Piechota M, Korostynski M, Solecki W, Gieryk A, Slezak M, Bilecki W, Ziolkowska B, Kostrzewa E, Cymerman I, Swiech L, et al: The dissection of transcriptional modules regulated by various drugs of abuse in the mouse striatum. Genome Biol 2010, 11(5):R48.

75. Carrasco MC, Vicens P, Vidal J, Redolat R: Effects of acute administration of bupropion on behavior in the elevated plus-maze test by NMRI mice. Prog Neuropsychopharmacol Biol Psychiatry 2004, 28(7):1135-1141.

76. Kameyama T, Nagasaka M, Yamada K: Effects of antidepressant drugs on a quickly-learned conditioned-suppression response in mice. Neuropharmacology 1985, 24(4):285-290.

77. Gladney M, Stanley RT, Hendricks SE: Anxiolytic activity of chloral hydrate and hydroxyzine. Pediatr Dent 1994, 16(3):183-189.

78. Olivier B, Leahy C, Mullen T, Paylor R, Groppi VE, Sarnyai Z, Brunner D: The $\mathrm{DBA} / 2 \mathrm{~J}$ strain and prepulse inhibition of startle: a model system to test antipsychotics? Psychopharmacology (Berl) 2001, 156(2-3):284-290.

79. Wang G, Fowler SC: Effects of haloperidol and clozapine on tongue dynamics during licking in CD-1, BALB/C and C57BL/6 mice. Psychopharmacology (Berl) 1999, 147(1):38-45.

80. Ziolkowska B, Gieryk A, Bilecki W, Wawrzczak-Bargiela A, Wedzony K, Chocyk A, Danielson PE, Thomas EA, Hilbush BS, Sutcliffe JG, et al: Regulation of alpha-synuclein expression in limbic and motor brain regions of morphine-treated mice. J Neurosci 2005, 25(20):4996-5003.

81. Gentleman RC, Carey VJ, Bates DM, Bolstad B, Dettling M, Dudoit S, Ellis B, Gautier L, Ge Y, Gentry J, et al: Bioconductor: open software development for computational biology and bioinformatics. Genome Biol 2004, 5(10):R80.

82. Sharova LV, Sharov AA, Nedorezov T, Piao Y, Shaik N, Ko MS: Database for mRNA half-life of 19977 genes obtained by DNA microarray analysis of pluripotent and differentiating mouse embryonic stem cells. DNA Res 2009, 16(1):45-58

83. da Huang W, Sherman BT, Tan Q, Collins JR, Alvord WG, Roayaei J, Stephens R, Baseler MW, Lane HC, Lempicki RA: The DAVID Gene Functional Classification Tool: a novel biological module-centric algorithm to functionally analyze large gene lists. Genome Biol 2007, 8(9):R183.

84. Khatri P, Draghici S, Ostermeier GC, Krawetz SA: Profiling gene expression using onto-express. Genomics 2002, 79(2):266-270.

85. Young WS 3rd, Bonner TI, Brann MR: Mesencephalic dopamine neurons regulate the expression of neuropeptide mRNAs in the rat forebrain. Proc Natl Acad Sci USA 1986, 83(24):9827-9831.

doi:10.1186/1471-2164-14-606

Cite this article as: Korostynski et al:: Novel drug-regulated transcriptional networks in brain reveal pharmacological properties of psychotropic drugs. BMC Genomics 2013 14:606. 